is well-defined, the body being flattened, whilst the posterior edges of the cephalothorax are prominent and somewhat hooked. The feet number five pairs, and are setose. No external ovisacs exist, and the antennæ are of simple conformation. Under the microscope the intestinal canal, filled with brownish matter, is seen to pulsate in rhythmical fashion. The abdomen is apparently composed of some four joints, and is terminated by two long caudal bristles. The eye is single, median, and red-coloured. In the absence of more definite characters, I should feel inclined to allocate the form near the genus Alteutha, of Baird, from the hooked character of the cephalo-thoracic edges. It differs from Alteutha, however, in the absence of the characteristic hooked edges of the fourth somite of the abdomen. The sudden appearance of myriads of these creatures in the tanks may probably be attributed to the recent favourable temperature; the eggs of the adults having lain dormant, as do the cyclops themselves, through the winter.

In the tanks are shown at present several large specimens of the lump-sucker (Cyclopterus lumpus). These fishes, as is well known, adhere by means of their sucker (formed by the modified ventral fins) to fixed objects. Watching a lump-sucker firmly attached to the glass of the tank, the idea occurred to me that the sucker may have been developed by natural selection, as a useful adjunct to the breathing-movements of the fish. When fixed, the fish appears to be perfectly at ease, and to breathe more fully and strongly than when swimming. The movements of the opercula, or gill-covers, when the fish was attached, were specially strong, as compared with their motion in the act of swimming. In a large-headed and heavy-bodied fish like Cyclopterus, any aid given to the respiratory movements would be a clear gain to the animal; and from a habit simply of resting on an object so as to afford leverage and play to the gills, the comparatively useless ventral fins may have become specially modified as a disc of attachment. The development of the sucking-disc and enlargement of the branchial cavity would thus proceed pari passu, and by natural selection the present exaggerated features of both organs would be attained. It would be interesting to know whether the history of cyclopterous development might or might not confirm these suggestions. The lumpsuckers have spawned in our tanks, but unfortunately there has been no attempt on the part of the males to fertilise the ova.

Edinburgh, June 14

ANDREW WILSON

Snails v. Glow-worms

SOME years ago I bronght three glow-worms from Wales to London, and at night 1 put them on the grass, when all showed their lights; but on looking for them a short time after, one had nearly disappeared, and on searching for it my hand came against something cold, and on taking it to the light $I$ found it was a snail-one of those which just now are very commonabout $\mathrm{I}^{1}$ inches long by $\frac{1}{4}$ inch diameter, and of a sandy colour. The brute had swallowed the "glow-worm, and I conld see the light shining inside!

As there are no glow-worms in this part of the country, I wish some one who has the chance would try the experiment again, by placing a glow-worm and a snail near to each other, and report the result.

Ferndene, June 22

R. S. NEWALI

\section{Oxygenated Rain}

THIS morning I have read Mr. Solly's note on this subject. Yesterday, June 2r, we had a thunderstorm, and while looking at the lightning I noticed that the rain falling on the windowglass had what I first thought were small particles of hail in the drops; but on magnifying it I found that the opacity was caused by a number of very small air-bubbles, which soon disappeared.

These drops fell during the shower, and only for an interval which I think did not exceed ten seconds, for I had only time to take the magnifier out of my pocket and observe a few drops, after which no more fell which contained air-bubbles.

One flash of lightning left a track which lasted about five seconds, and gradually faded. This was also observed by one of my family who was observing at a distance of $x, 000$ feet from where I was.

R. S. N.

\section{Butterfly Swarms}

The swarms of butterflies alluded to in NATURE, vol. $x x$. p. 183 , have been observed in various localities of $S$ witzerland-
Lausanne, Morges, the foot of the Jura, \&c. The passage lasted a long time, from one to four hours, on June 9 ; the species was Vanessa cardui. By comparing the hours and dates of the appearance in the various localities, I am convinced that it is simply due to the extraordinary local fecundity of this species, and not to a migration of butterflies from Africa or the shores of the Mediterranean, as various French and Swiss journals have supposed.

Morges, Switzerland, June 23

\section{Meteor}

I SAW a bright meteor at Bath last night. It flashed into sight at a spot some $10^{\circ}$ to the south of Arcturus at IO.38 P.M. The duration of its visibility was between two and three seconds, the direction of its path very nearly north-east to south-west, its brilliancy quite that of one of the so-called "fire-balls" in pyrotechnic displays. It travelled through about $25^{\circ}$ of arc, leaving a very faint trail, which however disappeared almost immediately. What struck me as particularly remarkable about the meteor was the decided bluish-green colour of its light.

June 19

C. Armbruster

\section{JOSEPH WILSON LOWRY, F.R.G.S.,}

DEATH has just erased another well-known name from the roll of workers on the Geological Survey of Great Britain, that of J. W. Lowry, the eminent engraver whose maps, sections, and plates of fossils form so interesting a part of the records of this important branch of the scientific public service.

Joseph Wilson Lowry was the only son of Wilson Lowry, F,R.S., and Rebecca Lowry, well known as a mineralogist some seventy years ago; he was born October 7,1803 . His father was the leading architectural and mechanical engraver of his time, and he trained up his son to follow his own pursuits. From his early youth his father's house was the resort of men of high intellectual culture, and his mother's pursuits leading her also to associate with the scientific men of the day, what wonder that young Lowry early imbibed his parent's tastes and became an ardent lover of all natural history studies and pursuits, an accomplished draughtsman, and a wellinformed scientific man.

His first practical effort was directed to the construction of a model in plaster of the Isle of Wight, geologically coloured, and divided transversely so as to give a section (also geologically coloured) through the centre of the island.

His pursuit of natural science led him early in life to become acquainted with John Phillips, at that time keeper of the Yorkshire Philosophical Society's Museum in York, and later on, when Assistant-General Secretary of the British Association for the Advancement of Science, or when associated with De la Beche on the Geological Survey, or when Professor of Geology in Oxford, until his death, Prof. Phillips remained the sincerely attached friend of $\mathrm{J}$. W. Lowry.

Lowry's first important work as an engraver was the execution of the plates for the "Encyclopædia Metropolitana." He also executed for Sir John Rennie a series of plates of London Bridge. For many years Mr. Lowry prepared all the engravings for Scott Russell illustrative of wave-lines and the contours of ships. Mr. Lowry designed and executed numerous maps and charts for the Society for Promoting Christian Knowledge, the illustrations for Weale's Scientific Series, the atlas of maps published by the Dispatch newspaper, the first really cheap and good atlas ever produced.

The plates illustrating Phillips's "Geology of Yorkshire," and many other scientific works, were engraved by Mr. Lowry. We are also indebted to him for the excellent series of Natural History Charts of British Fossils, stratigraphically arranged, British Tertiary Fossils, Recent and Fossil Crustacea, by Dr. H. Woodward and J. W. Salter, \&c. (Stanford's). 